\title{
Interaction between Medical Treatment and Minimally Invasive Surgical Treatment for the Malignancies of the Digestive Tract
}

\author{
Hiroyuki Kato $^{a}$ Hiroyuki Ono $^{b}$ Yasuo Hamamoto ${ }^{c}$ Hitoshi Ishikawad $^{d}$ \\ a First Department of Surgery, Dokkyo Medical University, Tochigi, Japan; bivision of Endoscopy, Shizuoka Cancer \\ Center, Shizuoka, Japan; ' Division of Gastroenterology and Hepatology, Keio University School of Medicine, Tokyo, \\ Japan; ${ }^{\mathrm{d}}$ Department of Radiation Oncology and Proton Medical Research Center, Faculty of Medicine, University of \\ Tsukuba, Ibaraki, Japan
}

\author{
Keywords \\ Gastric cancer - Colorectal cancer - Esophageal cancer . \\ Digestive tract $\cdot$ Medical treatment $\cdot$ Minimally invasive \\ surgery
}

\begin{abstract}
Recently, endoscopic diagnosis and treatment methods for early cancer in the digestive tract have made rapid progress. As for surgery, laparoscopic and thoracoscopic techniques have achieved rapidly advancing development in the last 2 decades. Early detection of the malignant lesion and the evolution of endoscopic and surgical device enabled in performing the minimally invasive surgery. Collaboration of medical treatment and minimally invasive surgery for advanced cancer is ongoing in the case of some conditions and in a few institutes. In this review, the contents of the core symposia on "Interaction between medical treatment and minimally invasive surgical treatment for the malignancies of the digestive tract", held at the 11, 12 and 13th annual meeting of the Japanese Gastroenterological Association, are summarized. At each annual meeting, the core symposium focused primarily on gastric, colorectal, and esophageal cancer treatment. For gastric cancer, endoscopic resection and laparoscopic surgery were 2 important key words.
\end{abstract}

\section{KARGER}

(c) 2018 S. Karger AG, Basel

E-Mail karger@karger.com

www.karger.com/dig
For colorectal cancer, multidisciplinary therapy was a major key word. And for esophageal cancer, endoscopic resection, chemoradiotherapy, thoracoscopic surgery and salvage surgery were key words. Patients' survival and quality of life are expected to further advance as a result of the collaboration of such therapeutic modalities.

(c) 2018 S. Karger AG, Basel

\section{Introduction}

The Japanese Gastroenterological Association (JGA) organizes core symposia at its annual meetings in order to enable continuous discussion on several important topics. One of the topics is "Contact point between medical treatment and minimally invasive surgical treatment for the malignancies of the digestive tract". Recent advances in diagnostic imaging have made it possible to detect early cancers in the gastrointestinal tract, which could be cured by endoscopic treatments or minimally invasive surgery $[1,2]$. On the other hand, limited surgery after multidisciplinary therapy (e.g., chemotherapy or chemoradiotherapy [CRT]) is one of the therapeutic strategies for treating locally advanced cancer. In this review, the contents of the core symposia are briefly summarized. 


\section{Forefront of Gastric Cancer Treatment (Core} Symposium 1 at the 11th Annual Meeting of JGA)

Efforts are continually being made in both the fields of surgery and medicine to minimize the treatment invasiveness so as to reduce the risks associated with the treatment and improve the post-treatment quality of life (QOL) in patients with early gastric cancer.

In the field of endoscopic treatment, strip biopsy [3] and endoscopic mucosal resection (EMR) $[4,5]$ were introduced successively in the 1980s; however, both entailed the problem of high recurrence rates owing to the limited extent of en bloc resection possible and the ambiguity of the pathologic diagnosis based on piecemeal resection. Subsequently, laparoscopic local resection of the stomach was developed as a minimally invasive treatment in the field of surgery in the 1990s [6]. This operative procedure, consisting of endoscopic full-thickness resection of the gastric wall, was an epochal method in which, for the first time, endoscopy was performed in combination with laparoscopic surgery. The advent of endoscopic submucosal dissection (ESD) in the 2000s enabled en bloc resection of even extensive lesions [6], and subsequent improvements in the devices and techniques of local injections have led to the widespread use of this treatment technique [7-9]; also, there has been an increase in the application of this procedure for the treatment of early gastric cancer [10].

From the point of view of surgical treatment, laparoscopic gastrectomy with regional lymphadenectomy has come to be widely performed since the advent of laparoscopy-assisted distal gastrectomy [11]. Laparoscopic gastrectomy has been on the path of becoming a standard treatment for Stage I disease not only because of the smaller surgical wound in the case of abdominal surgery but also because of reduced pain, blood loss, and more rapid postoperative recovery [12-14]. It has also been shown that laparoscopy-assisted distal gastrectomy is in no way inferior to abdominal surgery in terms of the therapeutic results, even as an additional surgical procedure, in patients who have undergone a noncurative resection by ESD [15]. However, since the postoperative disorders are associated with gastrectomy or lymphadenectomy, the so-called small stomach symptoms of dumping and diarrhea can also occur after this procedure just as in the case of abdominal surgery, which is a next-generation organ-conserving reduction surgery, with focus on the long-term QOL.

Recently, medical-surgical collaboration that was aimed at precise excision of lesions while conserving as much of the stomach as possible has led to the development of the so-called laparoscopic and endoscopic cooperative surgery (LECS) [16]. This method was, nevertheless, first devised for the treatment of gastrointestinal stromal tumors and has the drawback of being incapable of eliminating the risk of leakage of the gastric contents into the peritoneum upon opening of the stomach when it is applied for mucosal lesions, that is, for early gastric cancer. It is desirable to accomplish full-thickness resection of lesions without opening the stomach, as malignant cells could be suspended in the gastric contents even in cases of early gastric cancer [17]. In the 2010s, nonexposed endoscopic wallinversion surgery (NEWS) [18] and a combination of laparoscopic and endoscopic approaches to neoplasia with the nonexposure technique [19] were introduced in succession as innovative LECS procedures and they are already being used in the treatment of early gastric cancer.

In the treatment of early gastric cancer, it should be noted that curability should not be impaired on account of overenthusiastic pursuit of minimal invasiveness, while bearing in mind that unnecessary resection of the lymph nodes may indeed give rise to postoperative disorders. A prospective multicenter clinical trial on sentinel node (SN) biopsy in patients with cT1N0/cT2N0 gastric cancer measuring $\leq 4 \mathrm{~cm}$ in diameter was reported in 2013, with the results demonstrating a high SN identification rate $(98 \%)$ and a high lymph node metastasis diagnostic accuracy rate (99\%) [20]. These results compare favorably with the results of SN biopsies performed on breast cancer or malignant melanoma patients with advanced SN navigation surgery, and suggest the possibility that typical lymphadenectomy could be at least reduced in extent or altogether omitted in SN metastasis-negative patients.

If it becomes practicable to accurately select cases of early gastric cancer without lymph node metastasis by $\mathrm{SN}$ navigation surgery in the future, indications for such procedures as total stomach-conserving ESD, LECS, non-exposed endoscopic wall-inversion surgery, and combination of laparoscopic and endoscopic approaches to neoplasia with the nonexposure technique could be further expanded. While the oncological curability and safety of the procedures should be cautiously assessed, it is expected that an ultimate minimally invasive treatment for early gastric cancer will be established, and furthermore, that the current trend toward individualized treatment will be hastened and established. 


\section{Forefront of Colorectal Treatment (Core Symposium 1 at the 12th Annual Meeting of JGA)}

With prognostic comparison in the same stage, patients with rectal cancer have poor prognosis compared to colon cancer patients. A recurrent form of rectal cancer is characterized by local recurrence in addition to liver, lung, peritoneal dissemination, and lymph node recurrence. Therefore, control and treatment strategy for local recurrence is an important challenge for improving treatment outcomes of rectal cancer. To improve the outcome of rectal cancer treatment, preoperative concurrent CRT is performed in Europe and the United States, and lateral lymph node dissection (LLND) is performed in Japan.

Is an addition of CRT associated with minimally invasive treatment? The German rectal cancer trial group showed that sphincter preservation surgery was increasingly performed in patients needing abdomino-perineal resection [21]. In the pathological examination of the surgical specimen, intramural spread after CRT is of a low frequency and it is within about $1 \mathrm{~cm}$ [22]. It may contribute to expand the indication of sphincter-preservation surgery. However, as a disadvantage of CRT, the risk of anal dysfunction is increased [23]. There is a report showing that the postoperative anal function is decreased when the effect of preoperative CRT is strong in patients treated with intersphincteric resection [24]. Therefore, indication of sphincter-preserving surgery should be carefully decided. Another area that needs to be clarified is whether CRT achieves rectum preservation or not. In the GRECCAR2 trial [25], good clinical responders of CRT were assigned to local excision and rectal excision. Three-year overall survival and disease-free survival were almost the same in both groups.

In Japan, TME plus lateral LLND are standardized for T3 and T4 rectal cancer, and a satisfactory outcome is obtained [26]. Along with advances in systemic chemotherapy, neoadjuvant chemotherapy (NAC) is also being considered an attempt to improve the disadvantage of CRT. It is reported that NAC with oxaliplatin has high local effects like CRT and low frequency of lymph node metastasis $[27,28]$. A comparison of CRT and NAC was carried out pathologically. The grade of reduction after preoperative CRT was more prominent than that in NAC. T factor downstaging was more prominent in preoperative CRT than in NAC; however, $\mathrm{N}$ factor downstaging was more frequent in NAC than in preoperative CRT [29]. As a large-scale clinical trial, the NCCTG N 1048 trial is now in progress, and a comparison between CRT and NAC will become clear in the future.

Medical Treatment and Minimally Invasive Surgery of Digestive Tract Cancer
As for less invasive surgery, laparoscopic surgery is widely acceptable in treating early stage colorectal cancer. In JCOG0404 study, short-term surgical safety and clinical benefits of laparoscopic D3 dissection for stage II or III colon cancer were demonstrated [30]. Furthermore, survival outcomes following laparoscopic versus open D3 dissection were examined. Laparoscopic D3 surgery was inferior to open D3 surgery; laparoscopic D3 surgery could be an acceptable treatment option for patients with stage II or III colon cancer [31].

Colorectal cancer can be cured by metastatic resection even with distant metastasis. Even for distant metastasis, which is unresectable or marginally resectable, it is increasingly becoming resectable after chemotherapy. This strategy is named as conversion therapy. Several literature reports that chemotherapy with unresectable liver metastasis has made it possible to resect in $30-50 \%$ of patients and contributed to their prognoses [32-34]. Regarding addition of molecular target drug anti-EGFR agents, both response rate and resection rate were useful enough in the CELIM trial [35]. Also, a high response rate and resection rate by FOLFOXIRI regimen have been reported [36, 37]. Perioperative chemotherapy is being considered for resectable liver metastasis. In EORTC 40983 trial, prolongation of PFS is recognized, as compared with surgery alone, by performing FOLFOX with 6 courses before the operation and 6 courses after the operation [38]. Furthermore, in the new EPOC trial, it was investigated whether anti-EGFR agent was added to FOLFOX or CapeOX. Combination of anti-EGFR agent has been found to be without an additional treatment effect [39]. From analyzing hepatectomized patients, a nomogram was reported that can easily calculate the prognostic outcomes from 6 preoperative variables such as synchronous metastases, primary lymph node metastasis, number of liver tumors, tumor diameter, extrahepatic metastasis, and preoperative CA19-9 level [40].

In principle, hepatectomy is the first choice for topical treatment of liver metastasis, but there are reports in which radiofrequency ablation is used in combination to preserve residual liver volume. Results of radiofrequency ablation performed simultaneously with hepatectomy are slightly poor compared to the results of total liver tumor resection but are better than chemotherapy alone [41]. Although it can be considered a minimally invasive treatment for high-risk cases and cases of past-hepatectomy, as well as adaptation as cytoreduction combined with chemotherapy, it is a subject to be studied in the future. In future, further studies on combination of medical treatment and appropriate surgical treatment and personalized medicine are expected. 


\section{Forefront of Esophageal Cancer Treatment (Core Symposium 1 at the 13th Annual Meeting of JGA)}

Recent developments in endoscopic technology have enabled to detect superficial esophageal cancer [42], and endoscopic resection represented by EMR and ESD is increasingly being accepted as a standard therapy for mucosal (T1a) esophageal cancer in Japan. On the other hand, the standard treatment for submucosal (T1b) cancer has been a surgical resection with adequate LLND because of the high incidence of lymph node metastasis ( 40\%) [43]. However, because the diagnosis of T1a or T1b is difficult in some cases, sometimes T1a esophageal cancer is treated by transthoracic esophagectomy and sometimes T1b is treated by EMR/ ESD.

Transthoracic esopahgectomy for T1a cancer is too much invasive because surgical resection often deteriorates patient's general condition. Therefore, especially for early stage esophageal cancer, thoracoscopic esophagectomy as minimally invasive surgery has become more popular among surgeons in an effort to preserve patients' QOL [44-46]. While there are many retrospective studies demonstrating the superiority of thoracoscopic esophagectomy to transthoracic open esophagectomy $(\mathrm{OE})$, prospective studies are published from Western countries. The Eastern Cooperative Oncology Group (E2202) study demonstrated that minimally invasive esophagectomy (MIE; esophagectomy via the thoracoscopic and laparoscopic approach) is feasible and safe with low perioperative morbidity and mortality and good oncological result [47]. The TIME trial (traditional invasive vs. MIE, a multicenter, randomized trial) presented no differences in disease-free and overall 3-year survival for OE and MIE; therefore, this study supports the use of minimally invasive surgical techniques in the treatment of esophageal cancer [48]. In Japan, Takeuchi $\mathrm{H}$ et al. [49] compared short-term outcomes between OE and MI esophagectomy using the Japanese national clinical database. According to this study, operative time was significantly longer in the MIE group than that in the OE group, whereas blood loss was markedly less in the MIE group. MIE is beneficial in reducing postoperative respiratory complications. However, reoperation rate within 30 days was significantly higher in the MIE group than in the OE group. Based on these findings, a randomized phase III study (JCOG1409) was commenced to compare MIE with OE in terms of short-term and overall survival for stage IIII esophageal cancer [50].
A recent advance in techniques of EMR/ESD enables us to remove the clinical $\mathrm{T} 1 \mathrm{~b}$ tumor and gives us accurate diagnosis of depth of invasion [51]. However, the patients with $\mathrm{T} 1 \mathrm{~b}$ are at risk of lymph node metastasis and therefore, EMR/ESD alone cannot be considered curative. Therefore, surgical resection or CRT is added to pathological T1b tumor $[52,53]$. CRT is thought to be less invasive than surgical resection, although it is the measure for late cardiac and pulmonary adverse events. Thus, the multi-institutional Phase II trial to evaluate the efficacy and the safety of combined treatment of EMR and CRT for clinical stage I (cT1bN0) esophageal cancer (JCOG0508) was carried out [54]. The outcome of this trial is favorable (3-year survival of all registered patients is $92.6 \%$ ) and the strategy of additional CRT for $\mathrm{cT} 1 \mathrm{~b}$ esophageal squamous cell carcinoma according to the pathological findings after EMR/ESD may become a candidate of standard therapy because the survival rates are equal to those of esophagectomy.

As noted above, thoracoscopic esophagectomy and CRT must be regarded as minimally invasive treatments for noncurative cases after EMR/ESD for superficial esophageal cancer.

Recently, the practice of performing salvage surgery for the residue or recurrence after definitive CRT is increasing [55]. However, salvage esophagectomy is treated as a high-risk surgery because of high incidence of postoperative morbidity and mortality. For the improvement of short- and long-term postoperative superiority, many initiatives were undertaken. Thoracoscopic esophagectomy, transhiatal esophagectomy, lumphadenectomy without esophagectomy, and so on are reported as surgeries that constitute a minimally invasive salvage surgery. The success of a thoracoscopic and transhiatal salvage esophagectomy is based on the skill of surgeon, while they may be less invasive. For the common use of these surgeries, additional device and time will be needed. By the way, Watanabe $\mathrm{M}$ et al. [56] reported that patients with pretreatment or preoperative T1-2 tumors and those with relapse after CR are good candidates for salvage esophagectomy based on both short- and long-term outcomes. Therefore, minimally invasive salvage esophagectomy may become the appropriate form of treatment for such patients in the near future. With regard to salvage lymphadenectomy, a favorable outcome is reported in some reports $[57,58]$.

Despite the restrictions of surgical region (mediastinal lymph node recurrence is hard to resect), it must be a promising minimally invasive surgery for selected cases.
16

Digestion 2018;97:13-19

DOI: $10.1159 / 000484033$
Kato/Ono/Hamamoto/Ishikawa 


\section{Acknowledgment}

We express our sincere appreciation to all authors who contributed to the core symposia.

\section{Disclosure Statement}

The authors declare that no financial conflict or conflicts of interest exist in relation to the content of the article.

\section{References}

1 Sanomura M, Tanaka S, Sasaki Y, Fukunishi S, Higuchi K: Endoscopic diagnosis of the invasion depth of $\mathrm{T} 1$ colorectal carcinoma for endoscopic resection by using narrow-band imaging magnification as total excisional biopsy. Digestion 2016;94:106-113.

2 Kikuchi D, Iizuka T, Yamada A, Nomura K, Kuribayashi Y, Kimura R, Hoteya S, Kaise M: Feasibility of a newly developed thumb control device for simultaneous manipulation of the endoscope and treatment devices in endoscopic submucosal dissection: a clinical feasibility study. Digestion 2016;94:123-128.

3 Tada M, Karita M, Yanai H, akemoto T: Endoscopic therapy of early gastric cancer by strip biopsy. Gan To Kagaku Ryoho 1988;15: 1460-1465

4 Hirao M, Masuda K, Asanuma T, Naka H, Noda K, Matsuura K, Yamaguchi O, Ueda N: Endoscopic resection of early gastric cancer and other tumors with local injection of hypertonic saline-epinephrine. Gastrointest Endosc 1988;34:264-269.

5 Inoue $\mathrm{H}$, Takeshita K, Hori H, Muraoka Y, Yoneshima H, Endo M: Endoscopic mucosal resection with a cap-fitted panendoscope for esophagus, stomach, and colon mucosal lesions. Gastrointest Endosc 1993;39:58-62.

6 Ohgami M, Kumai K, Otani Y, Wakabayashi G, Kubota T, Kitajima M: Laparoscopic wedge resection of the stomach for early gastric cancer using a lesion-lifting method. Dig Surg 1994;11:64-67.

7 Ono H, Kondo H, Gotoda T, Shirao K, Yamaguchi H, Saito D, Hosokawa K, Shimoda T, Yoshida S: Endoscopic mucosal resection for treatment of early gastric cancer. Gut 2001;48: 225-229.

8 Oyama T, Kikuchi Y: Aggressive endoscopic mucosal resection in the upper GI tract hook knife EMR method. Minim Invasive Ther Allied Technol 2002;11:291-295.

9 Yamamoto H, Kawata H, Sunada K, Satoh K, Kaneko Y, Ido K, Sugano K: Success rate of curative endoscopic mucosal resection with circumferential mucosal incision assisted by submucosal injection of sodium hyaluronate. Gastrointest Endosc 2002;56:507-512.

10 Dai J, Huang X, Lu B, Jin H, Meng L: Evaluation of the expanded criteria of endoscopic submucosal dissection for early gastric cancers: a meta-analysis. Digestion 2015;92:227-235.

11 Kitano S, Iso Y, Moriyama M, Sugimachi K: Laparoscopy-assisted Billroth I gastrectomy. Surg Laparosc Endosc 1994;4:146-148.

12 Katai H, Sasako M, Fukuda H, Nakamura K, Hiki N, Saka M, Yamaue H, Yoshikawa T, Ko- jima K; the JCOG Gastric Cancer Surgical Study Group: Safety and feasibility of laparoscopy-assisted distal gastrectomy with suprapancreatic nodal dissection for clinical stage I gastric cancer: a multicenter phase II trial (JCOG 0703). Gastric Cancer 2010;13:238-244.

13 Katai H, Mizusawa J, Katayama H, Takagi M, Yoshikawa T, Fukunaga T, Terashima M, Misawa K, Teshima S, Koeda K, Nunobe S, Fukushima N, Yasuda T, Asao Y, Fujiwara Y, Sasako M: Short-term surgical outcomes from a phase III study of laparoscopy-assisted versus open distal gastrectomy with nodal dissection for clinical stage IA/IB gastric cancer: Japan Clinical Oncology Group Study JCOG0912. Gastric Cancer 2017;20:699-708.

14 Kim W, Kim HH, Han SU, Kim MC, Hyung WJ, Ryu SW, Cho GS, Kim CY, Yang HK, Park DJ, Song KY, Lee SI, Ryu SY, Lee JH, Lee HJ: Decreased morbidity of laparoscopic distal gastrectomy compared with open distal gastrectomy for stage I gastric cancer. Ann Surg 2016;263:28-35.

15 Suzuki T, Tanabe K, Vu DTA, Misumi T, Fujikuni N, Tokumoto N, Ohdan H: Safety and efficacy of laparoscopy-assisted gastrectomy after endoscopic submucosal dissection for early gastric cancer: a retrospective report. Journal of Cancer Therapy 2013;4:54-60.

16 Hiki Y, Yamamoto Y, Fukunaga T, Yamaguchi T, Nunobe S, Tokunaga M, Miki A, Ohyama S, Seto Y: Laparoscopic and endoscopic cooperative surgery for gastrointestinal stromal tumor dissection. Surg Endosc 2008;22: 1729-1735.

17 Han TS, Kong SH, Lee HJ, Ahn HS, Hur K, Yu J, Kim WH, Yang HK: Dissemination of free cells from the gastric lumen and from perigastric lymphovascular pedicles during radical gastric cancer surgery. Ann Surg Oncol 2011; 18:2818-2825.

18 Goto O, Mitsui T, Fujishiro M, Wada I, Shimizu N, Seto Y, Koike K: New method of endoscopic full-thickness resection: a pilot study of non-exposed endoscopic wall-inversion surgery in an ex vivo porcine model. Gastric Cancer 2011;14:183-187.

19 Inoue $H$, Ikeda $H$, Hosoya $T$, Yoshida A, Onimaru M, Suzuki M, Kudo SE: Endoscopic mucosal resection, endoscopic submucosal dissection, and beyond: full-layer resection for gastric cancer with nonexposure technique (CLEAN-NET). Surg Oncol Clin N Am 2012;21:129-140.

20 Kitagawa Y, Takeuchi H, Takagi Y, Natsugoe S, Terashima M, Murakami N, Fujimura T, Tsujimoto H, Hayashi H, Yoshizumi N, Taka- gane A, Mohri Y, Nabeshima K, Uenosono Y, Kinami S, Sakamoto J, Morita S, Aikou T, Miwa K, Kitajima M: Sentinel node mapping for gastric cancer: a prospective multicenter trial in Japan. J Clin Oncol 2013;31:3704-3710.

21 Sauer R, Becker H, Hohenberger W, Rodel C, Wittekind C, Fietkau R, Martus P, Tschmelitsch J, Hager E, Hess CF, Karstens JH, Liersch T, Schmidberger H, Raab R; German Rectal Cancer Study Group: Preoperative versus postoperative chemoradiotherapy for rectal cancer. N Engl J Med 2004;351: 1731-1740.

22 Mezhir JJ, Shia J, Riedel E, Temple LK, Nash GM, Weiser MR, Paty PB, Wong WD, Guillem JG: Whole-mount pathologic analysis of rectal cancer following neoadjuvant therapy: implications of margin status on long-term oncologic outcome. Ann Surg 2012;256:274279.

23 Pollack J, Holm T, Cedermark B, Holmstrom B, Mellgren A: Long-term effect of preoperative radiation therapy on anorectal function. Dis Colon Rectum 2006;49:345-352.

24 Nishizawa Y, Saito N, Fujii S, Ito M, Sugito M, Kobayashi A, Nishizawa Y: Association between anal function and therapeutic effect after preoperative chemoradiotherapy followed by intersphincteric resection. Dig Surg 2012; 29:439-445.

25 Rullier E, Rouanet P, Tuech JJ, Valverde A, Lelong B, Rivoire M, Faucheron JL, Jafari M, Portier G, Meunier B, Sileznieff I, Prudhomme M, Marchal F, Pocard M, Pezet D, Rullier A, Vendrely V, Denost Q, Asselineau J, Doussau A: Organ preservation for rectal cancer (GRECCAR 2): a prospective, randomised, open-label, multicentre, phase 3 trial. Lancet 2017;390:469-479.

26 Sugihara K, Kobayashi H, Kato T, Mori T, Mochizuki H, Kameoka S, Shirouzu K, Muto $\mathrm{T}$ : Indication and benefit of pelvic sidewall dissection for rectal cancer. Dis Colon Rectum 2006;49:1663-1672.

27 Suarez J, Amat I, Vera R, Balen E, Gomez M, Lera JM: Pathologic response of primary rectal cancer to oxaliplatin-based chemotherapy. Clin Colon Rectal Surg 2011;24:119-124.

28 Sawayama H, Hayashi N, Honda S, Baba Y, Toyama E, Watanabe M, Takamori H, Beppu T, Baba H: Treatment results of FOLFOX chemotherapy before surgery for lymph node metastasis of advanced colorectal cancer with synchronous liver metastasis: the status of LN metastasis and vessel invasions at the primary site in patients who responded to FOLFOX. Int J Clin Oncol 2010;15:70-76.
Medical Treatment and Minimally

Invasive Surgery of Digestive Tract Cancer
Digestion 2018;97:13-19

DOI: $10.1159 / 000484033$ 
29 Sakuyama N, Kojima M, Kawano S, Akimoto T, Saito N, Ito M, Ochiai A: Histological differences between preoperative chemoradiotherapy and chemotherapy for rectal cancer: a clinicopathological study. Pathol Int 2016; 66:273-280

30 Yamamoto S1, Inomata $M$, Katayama $H$, Mizusawa J, Etoh T, Konishi F, Sugihara K, Watanabe M, Moriya Y, Kitano S; Japan Clinical Oncology Group Colorectal Cancer Study Group: Short-term surgical outcomes from a randomized controlled trial to evaluate laparoscopic and open D3 dissection for stage II/III colon cancer: Japan clinical oncology group study JCOG 0404. Ann Surg 2014;260:23-30.

31 Kitano S, Inomata M, Mizusawa J, Katayama $\mathrm{H}$, Watanabe M, Yamamoto S, Ito M, Saito S, Fujii S, Konishi F, Saida Y, Hasegawa H, Akagi T, Sugihara K, Yamaguchi T, Masaki T, Fukunaga $\mathrm{Y}$, Murata K, Okajima M, Moriya Y, Shimada Y: Survival outcomes following laparoscopic versus open D3 dissection for stage II or III colon cancer (JCOG0404): a phase 3, randomised controlled trial. Lancet Gastroenterol Hepatol 2017;2:261-268.

32 Skof E, Rebersek M, Hlebanja Z, Ocvirk J: Capecitabine plus Irinotecan (XELIRI regimen) compared to 5-FU/LV plus Irinotecan (FOLFIRI regimen) as neoadjuvant treatment for patients with unresectable liver-only metastases of metastatic colorectal cancer: a randomised prospective phase II trial. BMC Cancer 2009;9:120.

33 Beppu T, Hayashi N, Masuda T, Komori H, Horino K, Hayashi $\mathrm{H}$, Okabe $\mathrm{H}$, Baba Y, Kinoshita K, Akira C, Watanebe M, Takamori H, Baba H: FOLFOX enables high resectability and excellent prognosis for initially unresectable colorectal liver metastases. Anticancer Res 2010;30:1015-1020.

34 Takahashi T, Shibata Y, Tojima Y, Tsuboi K, Sakamoto E, Kunieda K, Matsuoka H, Suzumura K, Sato M, Naganuma T, Sakamoto J, Morita S, Kondo K: Multicenter phase II study of modified FOLFOX6 as neoadjuvant chemotherapy for patients with unresectable liver-only metastases from colorectal cancer in Japan: ROOF study. Int J Clin Oncol 2013; 18:335-342.

35 Folprecht G, Gruenberger T, Bechstein WO, Raab HR, Lordick F, Hartmann JT, Lang H, Frilling A, Stoehlmacher J, Weitz J, Konopke R, Stroszczynski C, Liersch T, Ockert D, Herrmann T, Goekkurt E, Parisi F, Kohne CH: Tumour response and secondary resectability of colorectal liver metastases following neoadjuvant chemotherapy with cetuximab: the CELIM randomized phase 2 trial. Lancet Oncol 2010;11:38-47.

36 Masi G, Loupakis F, Pollina L, Vasile E, Cupini S, Ricci S, Brunetti IM, Ferraldeschi R, Naso G, Filipponi F, Pietrabissa A, Goletti O, Baldi G, Fornaro L, Andreuccetti M, Falcone A: Long-term outcome of initially unresectable metastatic colorectal cancer patients treated with 5-fluorouracil/leucovorin, oxaliplatin, and irinotecan (FOLFOXIRI) followed by radical surgery of metastases. Ann Surg 2009; 249:420-425.

37 Ychou M, Rivoire M, Thezenas S, Quenet F, Delpero JR, Rebischung C, Letoublon C, Guimbaud R, Francois E, Ducreux M, Desseigne F, Fabre JM, Assenat E: A randomized phase II trial of three intensified chemotherapy regimens in first-line treatment of colorectal cancer patients with initially unresectable or not optimally resectable liver metastases. The METHEP trial. Ann Surg Oncol 2013;20: 4289-4297.

38 Nordlinger B, Sorbye H, Glimelius B, Poston GJ, Schlag PM, Rougier P, Bechstein WO, Primrose JN, Walpole ET, Finch-Jones M, Jaeck D, Mirza D, Parks RW, Collette L, Praet M, Bethe U, Van Cutsem E, Scheithauer W, Gruenberger T; EORTC Gastro-Intestinal Tract Cancer Group, Cancer Research UK; Arbeitsgruppe Lebermetastasen und-tumoren in der Chirurgischen Arbeitsgemeinschaft Onkologie (ALM-CAO), Australasian Gastro-Intestinal Trials Group (AGITG), Federation Francophone de Cancerologie Digestive (FFCD): Perioperative chemotherapy with FOLFOX4 and surgery versus surgery alone for resectable liver metastases from colorectal cancer (EORTC Intergroup trial 40983): a randomised controlled trial. Lancet 2008;371: 1007-1016.

39 Primrose J, Falk S, Finch-Jones M, Valle J, O'Reilly D, Siriwardena A, Hornbuckle J, Peterson M, Rees M, Iveson T, Hickish T, Butler R, Stanton L, Dixon E, Little L, Bowers M, Pugh S, Garden OJ, Cunningham D, Maughan $\mathrm{T}$, Bridgewater J: Systemic chemotherapy with or without cetuximab in patients with resectable colorectal liver metastasis: the New EPOC randomized controlled trial. Lancet Oncol 2014;15:601-611.

40 Beppu T, Sakamoto Y, Hasegawa K, Honda G, Tanaka K, Kotera Y, Nitta H, Yoshidome H, Hatano E, Ueno M, Takamura H, Baba H, Kosuge T, Kokudo N, Takahashi K, Endo I, Wakabayashi G, Miyazaki M, Uemoto S, Ohta T, Kikuchi K, Yamaue H, Yamamoto M, Takada T: A nomogram predicting diseasefree survival in patients with colorectal liver metastases treated with hepatic resection: multicenter data collection as a Project Study for hepatic surgery of the Japanese society of hepato-biliary-pancreatic surgery. J Hepatobiliary Pancreat Sci 2012;19:72-84.

41 Abdalla EK, Vauthey JN, Ellis LM, Ellis V, Pollock R, Broglio KR, Hess K, Curley SA: Recurrence and outcomes following hepatic resection, radiofrequency ablation, and combined resection/ablation for colorectal liver metastases. Ann Surg 2004;239:818-825; discussion $825-827$.

42 Matsui A, Kuribayashi Y, Nomura K, Tanaka T, Toba T, Yamada A, Furuhata T, Yamashita S, Kikuchi D, Mitani T, Ogawa O, Iizuka T, Hoteya S, Kaise M: Conventional white light endoscopic features of small superficial barrett's esophageal adenocarcinoma. Digestion 2016;93:47-52.
43 Kato H, Tachimori Y, Mizobuchi S, Igaki H, Ochiai A. Cervical, mediastinal, and abdominal lymph node dissection (three-field dissection) for superficial esophageal carcinoma of the thoracic esophagus. Cancer 1993;72: 2879-2882.

44 Noshiro H, Yoda Y, Hiraki M, Kono H, Miyake S, Uchiyama A, Nagai E: Survival outcomes of 220 consecutive patients with threestaged thoracoscopic esophagectomy. Dis Esophagus 2016;29:1090-1099.

45 Osugi $\mathrm{H}$, Takemura M, Higashino M, Takada N, Lee S, Kinoshita H: A comparison of videoassisted thoracoscopic oesophagectomy and radical lymph node dissection for squamous cell cancer of the oesophagus with open operation. Br J Surg 2003;90:108-113.

46 Ozawa S, Ito E, Kazuno A, Chino O, Nakui M, Yamamoto S, Shimada H, Makuuchi H: Thoracoscopic esophagectomy while in a prone position for esophageal cancer: a preceding anterior approach method. Surg Endosc 2013; 27:40-47.

47 Luketich JD, Pennathur A, Franchetti Y, Catalano PJ, Swanson S, Sugarbaker DJ, De Hoyos A, Maddaus MA, Nguyen NT, Benson $A B$, Fernando HC: Minimally invasive esophagectomy: results of a prospective phase II multicenter trial-the eastern cooperative oncology group (E2202) study. Ann Surg 2015; 261:702-707.

48 Straatman J, van der Wielen N, Cuesta MA, Daams F, Roig Garcia J, Bonavina L, Rosman C, van Berge Henegouwen MI, Gisbertz SS, van der Peet DL: Minimally invasive versus open esophageal resection: three-year followup of the previously reported randomized controlled trial: the TIME Trial. Ann Surg 2017;266:232-236.

49 Takeuchi $\mathrm{H}$, Miyata $\mathrm{H}$, Ozawa S, Udagawa $\mathrm{H}$, Osugi H, Matsubara H, Konno H, Seto Y, Kitagawa Y: Comparison of short-term outcomes between open and minimally invasive esophagectomy for esophageal cancer using a nationwide database in Japan. Ann Surg Oncol 2017;24:1821-1827.

50 Kataoka K, Takeuchi H, Mizusawa J, Ando M, Tsubosa Y, Koyanagi K, Daiko H, Matsuda S, Nakamura K, Kato K, Kitagawa Y; Japan Esophageal Oncology Group/Japan Clinical Oncology Group: A randomized Phase III trial of thoracoscopic versus open esophagectomy for thoracic esophageal cancer: Japan Clinical Oncology Group Study JCOG1409. Jpn J Clin Oncol 2016;46:174-177.

51 Sgourakis G, Gockel I, Lang H: Endoscopic and surgical resection of T1a/T1b esophageal neoplasms: a systematic review. World J Gastroenterol 2013;19:1424-1437.

52 Motoyama S, Jin M, Matsuhashi T, Nanjo H, Ishiyama K, Sato Y, Yoshino K, Sasaki T, Wakita A, Saito H, Minamiya Y, Ohnishi $\mathrm{H}$, Ogawa J: Outcomes of patients receiving additional esophagectomy after endoscopic resection for clinically mucosal, but pathologically submucosal, squamous cell carcinoma of the esophagus. Surg Today 2013;43:638-642. 
53 Ikeda A, Hoshi N, Yoshizaki T, Fujishima Y, Ishida T, Morita Y, Ejima Y, Toyonaga T, Kakechi Y, Yokosaki H, Azuma T: Endoscopic submucosal dissection (ESD) with additional therapy for superficial esophageal cancer with submucosal invasion. Intern Med 2015;54: 2803-2813.

54 Kurokawa Y, Muto M, Minashi K, Boku N, Fukuda H; Gastrointestinal Oncology Study Group of Japan Clinical Oncology Group (JCOG): A phase II trial of combined treatment of endoscopic mucosal resection and chemoradiotherapy for clinical stage I esophageal carcinoma: Japan Clinical Oncology Group Study JCOG0508. Jpn J Clin Oncol 2009;39:686-689.
55 Kumagai K, Mariosa D, Tsai JA, Nilsson M, Ye W, Lundell L, Rouvelas I: Systematic review and meta-analysis on the significance of salvage esophagectomy for persistent or recurrent esophageal squamous cell carcinoma after definitive chemoradiotherapy. Dis Esophagus 2016;29:734-739.

56 Watanabe M, Mine S, Nishida K, Yamada K, Shigaki H, Matsumoto A, Sano T: Salvage esophagectomy after definitive chemoradiotherapy for patients with esophageal squamous cell carcinoma: who really benefits from this high-risk surgery? Ann Surg Oncol 2015; 22:4438-4444.
57 Nakajima M, Domeki Y, Satomura H, Takahashi M, Sugawara A, Muroi H, Sasaki K, Yamaguchi S, Miyazaki T, Kuwano H, Kato H: Salvage lymphadenectomy for recurrent esophageal cancer after chemoradiotherapy. Int Surg 2014;99:452-457.

58 Watanabe M, Mine S, Yamada K, Shigaki H, Baba Y, Yoshida N, Kajiyama K, Yamamoto N, Sano T, Baba H: Outcomes of lymphadenectomy for lymph node recurrence after esophagectomy or definitive chemoradiotherapy for squamous cell carcinoma of the esophagus. Gen Thorac Cardiovasc Surg 2014;62:685-692. 